\title{
Retraction Note to: Rock and soil reconstruction of mountain slope based on embedded Internet of things and evaluation of college students' physical health
}

\author{
Linlin $\mathrm{Li}^{1}$
}

Published online: 3 November 2021

(c) Saudi Society for Geosciences 2021

Retraction Note to: Arabian Journal of Geosciences (2021) 14: 1790 https://doi.org/10.1007/s12517-021-08019-w

The Editor-in-Chief and the Publisher have retracted this article because the content of this article is nonsensical. The peer review process was not carried out in accordance with the Publisher's peer review policy. The author has not responded to correspondence regarding this retraction.

The original article can be found online at https://doi.org/10.1007/ s12517-021-08019-w.

Linlin Li

wuhenxxg1979@163.com

1 PE College of Huanghuai University, Zhumadian, Henan,

China 